\title{
Overdiagnosis of COPD in hospitalized patients
}

This article was published in the following Dove Press journal:

International Journal of COPD

II August 2017

Number of times this article has been viewed

\author{
Kerry Spero' \\ Ghiath Bayasi² \\ Linda Beaudry ${ }^{3}$ \\ Kimberly R Barber ${ }^{4}$ \\ Fahim Khorfan ${ }^{2}$ \\ 'Department of Medical Education, \\ Genesys Regional Medical Center, \\ Grand Blanc, ${ }^{2}$ Department of \\ Pulmonary and Critical Care \\ Medicine, Michigan State University, \\ East Lansing, ${ }^{3}$ Department of \\ Respiratory Therapy, ${ }^{4}$ Department of \\ Research, Genesys Regional Medical \\ Center, Grand Blanc, MI, USA
}

Correspondence: Kimberly R Barber Department of Research, Genesys Regional Medical Center, Suite 2442, Grand Blanc, MI 48439, USA

Tel +l 8I06067724
Email kbarber@genesys.org

Background: The diagnosis of chronic obstructive pulmonary disease (COPD) is usually made based on history and physical exam alone. Symptoms of dyspnea, cough, and wheeze are nonspecific and attributable to a variety of diseases. Confirmatory testing to verify the airflow obstruction is available but rarely used, which may result in substantial misdiagnoses of COPD. The aim of this study is to evaluate the use of confirmatory testing and assess the accuracy of the diagnosis.

Methods: From January 2011 through December 2013, 6,018 patients with COPD as a principal or leading diagnosis were admitted at a community teaching hospital. Of those, only $504(8.4 \%)$ patients had spirometry performed during hospitalization. The studies were reviewed by two board-certified pulmonologists to verify presence of persistent airflow obstruction. Charts of these patients were then examined to determine if the spirometry results had changed the diagnosis or the treatment plan for these patients.

Results: Spirometry confirmed the diagnosis of COPD in 270 patients $(69.2 \%)$ treated as COPD during their hospitalization. Restrictive lung disease was found to be present in 104 patients $(26.6 \%)$ and normal in 16 patients $(4.2 \%)$. Factors predictive of airflow obstruction included smoking status and higher pack-year history. Negative predictive factors included higher body mass index (BMI) and other medical comorbidities. These patients were significantly more likely to be misdiagnosed and mistreated as COPD.

Conclusion: Up to a third of patients diagnosed and treated as COPD in the hospital may be inaccurately diagnosed as COPD based on confirmatory spirometry testing. Factors contributing to the inaccuracy of diagnosis include less smoking history, high BMI, and associated comorbidities.

Keywords: COPD, spirometry, overdiagnosis, misdiagnosis

\section{Introduction}

Chronic obstructive pulmonary disease (COPD) is the third leading cause of death among people over 65 years $^{1}$ and disease exacerbation accounts for almost 1 million hospitalizations each year in the US. ${ }^{2}$ Indeed, COPD is a worldwide issue and is thought to cause 3 million deaths annually. ${ }^{3}$ The clinical diagnosis of COPD should be considered among patients with smoking history, dyspnea, chronic cough, and/or sputum production. The diagnosis of COPD based on symptoms alone is thought to overestimate true COPD prevalence ${ }^{4}$ as these symptoms are shared by many pulmonary and non-pulmonary diagnoses. ${ }^{4-9}$ Morbid obesity, vocal cord dysfunction, asthma, restrictive lung disease, congestive heart failure, and pulmonary fibrosis may have a similar presentation. ${ }^{8,9}$ Clinical diagnosis of COPD and International Classification of Diseases (ICD) codes for COPD are used in hospitalized patients without validation of the correct diagnosis. Moreover, ICD codes are used to identify patients for quality improvement initiatives. ${ }^{10}$

COPD is characterized by persistent airflow limitation. This is best measured by spirometry, which is a widely available and reproducible test of lung function, proven 
effective even in diagnosing patients who are hospitalized with respiratory complaints. ${ }^{11}$ Post-bronchodilator forced expiratory volume in one second to forced vital capacity ratio $\left(\mathrm{FEV}_{1} / \mathrm{FVC}\right)$ less than 0.70 in a well-performed test confirms the presence of persistent airflow limitation and the presence of COPD. ${ }^{12}$ The underdiagnosis of COPD is well known ${ }^{13}$ and currently there is also a concern of "overdiagnosis" of COPD using clinical and ICD codes. This issue was investigated recently in the outpatient/primary care setting, academic institutions, and veterans hospitals. ${ }^{14-20}$ In this study, the use of spirometry in hospitalized patients and the frequency of misdiagnosis of COPD in a community-based teaching hospital are examined.

\section{Materials and methods}

\section{Study design, setting, and subjects}

Data collected from patients admitted to a community, university-affiliated teaching hospital in Michigan from January 2011 through December 2013 were examined in this retrospective study. Criteria for admission to the study were adult patients aged 18 years and older. In order to be included in the study, the patients needed to present with respiratory complaints, with COPD as a principle or leading diagnosis. Charts were identified by the ICD, Ninth Revision (ICD-9) codes. The diagnosis of COPD was verified during chart review of the history and physical, emergency department records, consultation reports, and/or discharge summary. The ICD-9 codes searched for were 490 Bronchitis Not Otherwise Specified (NOS), 491 Chronic Bronchitis, 492 Emphysema, 496 Chronic Airway Obstruction/COPD NOS, 518.1 Interstitial Emphysema, 518.81 Acute Respiratory Failure, 518.83 Chronic Respiratory Failure, and 518.84 Acute and Chronic Respiratory Failure. Any of these ICD-9 codes could have been the principal diagnosis. If one of the respiratory failure codes was the principal diagnosis, one of the COPD ICD-9 codes was included as a secondary code. The Institutional Review Board (IRB) of Genesys Health System approved this study (approval number 589178-3). The Genesys IRB approved a waiver of consent for the study based on its retrospective design; it involved no more than minimal risk and it was impractical to contact every patient in the study due to the passage of time. Confidentiality of the data was protected with the use of subject numbers and no personal health identifiers on the data sheets.

\section{Data collection}

During the two-year time period, 6,018 patients were admitted who met the criteria for the study. Of these, 504 patients
(8.4\%) had spirometric assessment of their pulmonary function during the hospitalization and were thus further studied. The pulmonary function tests (PFTs) were independently read by two board-certified pulmonologists using standard American Thoracic Society-European Respiratory Society (ATS-ERS) criteria for acceptability and reproducibility. ${ }^{22}$ Of the total spirometric studies, 390 were considered valid studies based on ATS-ERS criteria. Common reasons for exclusion were recorded by the performing technologists and included patients who were too dyspneic to perform the test, had a severe cough, and who were unable to follow the instructions of the test due to confusion or dementia.

The spirometry records were considered diagnostic for COPD by the Global Initiative for Chronic Obstructive Lung Disease (GOLD) criteria if the post-bronchodilator $\mathrm{FEV}_{1} /$ FVC ratio was less than 0.70 . With aging, it is known that the $\mathrm{FEV}_{1}$ declines proportionally more than the FVC. Therefore, the fixed ratio proposed by GOLD may tend to overestimate COPD in elderly patients. ${ }^{16,17}$ GOLD criteria was mainly used in this study to define COPD. The spirometry records were additionally analyzed using the lower limit of normal (LLN) criteria. ${ }^{21}$ This additional analysis was considered relevant due to the mean age of the study participants being older than 60 years.

The studies that had $\mathrm{FEV}_{1} / \mathrm{FVC}$ ratio of 70 or greater were considered as not obstructive. They were thereby classified as normal if the FVC and $\mathrm{FEV}_{1}$ were both greater than $80 \%$ or as restrictive if the FVC and $\mathrm{FEV}_{1}$ were less than $80 \%$. The degree of bronchial hyperresponsiveness was assessed as defined as a post-bronchodilator increase in either FVC or $\mathrm{FEV}_{1}$ by at least $12 \%$ and at least $200 \mathrm{~mL}$.

Following the PFT review, demographic and historical data were collected from all patients. Demographic data included age, sex, race, and body mass index (BMI). Patients were considered underweight if BMI was less than $18.5 \mathrm{~kg} / \mathrm{m}^{2}$, normal weight if BMI was $18.6-24.9 \mathrm{~kg} / \mathrm{m}^{2}$, overweight if BMI was $25-29.9 \mathrm{~kg} / \mathrm{m}^{2}$, and obese if BMI was greater than $30 \mathrm{~kg} / \mathrm{m}^{2}$.

Historical data included whether a patient was a current smoker, former smoker, or never smoker. A current smoker was defined as someone who had smoked cigarettes in the month preceding hospitalization. A former smoker was defined as someone who had smoked at least one pack-year and had quit more than one month prior to hospitalization. A never smoker was defined as someone with no significant personal history of smoking (less than one pack-year). Current and former smokers were stratified based on the number of pack-years. Medical comorbid conditions were drawn 
from chart review, including hypertension, coronary artery disease, congestive heart failure, chronic kidney disease, and obstructive sleep apnea.

Additional information was obtained from the charts of patients who were classified as not COPD to see if the spirometry led to a change in the treatment plan.

\section{Statistical analysis}

Using 2-sample $t$-test between rates, patients with COPD were compared to those without COPD with regard to sex, race, smoking history, and medical comorbidities. Age and BMI were compared using an independent group $t$-test between means. Significance was set at $P<0.05$. Because the main interest of the study was to evaluate the overdiagnosis of COPD, for the purposes of statistical analysis, the subgroups of restrictive lung disease and normal spirometry were combined together and compared to those with COPD.

\section{Results}

A total of 8.4\% (504 of 6,018) patients admitted with COPD had a spirometry study performed during their hospitalization. A total of 36 spirometries were excluded because they had pre-bronchodilator spirometry only, and thus it was not possible to use GOLD criteria for diagnosis. A total of 390 of $468(83.3 \%)$ patients tested were able to adequately perform spirometry to meet acceptability and reproducibility (Figure 1).

A total of 78 tests were excluded because they did not meet ATS-ERS criteria. The main reason was due to the patient being unable to exhale for at least six seconds. The respiratory technician noted several other reasons for the patients' inability to perform acceptable tests, including severe cough, dyspnea, weakness, or confusion and inability to follow the instructions from the technician.

Out of 390 valid spirometries, 270 (69.2\%) spirometric measurements confirmed the diagnosis of COPD. The COPD patients $(\mathrm{N}=270)$ were compared to patients given the diagnosis of restrictive $(\mathrm{N}=104)$ and normal $(\mathrm{N}=16)$ to identify if there were any factors that were predictive of COPD. The mean age for patients with COPD and those without COPD were similar at 70 and 68 years $(\mathrm{SD}=12.29$ and 13.99, respectively). The groups were also similar in racial characteristics and sex. Smoking history was significantly different between those with COPD and other diagnosis. Patients with COPD were statistically more likely to be current or former smokers $(P=0.03)$, while patients without COPD were far more likely to be never smokers $(P=0.0001)$. Individual pack-year history of smoking was also significant.

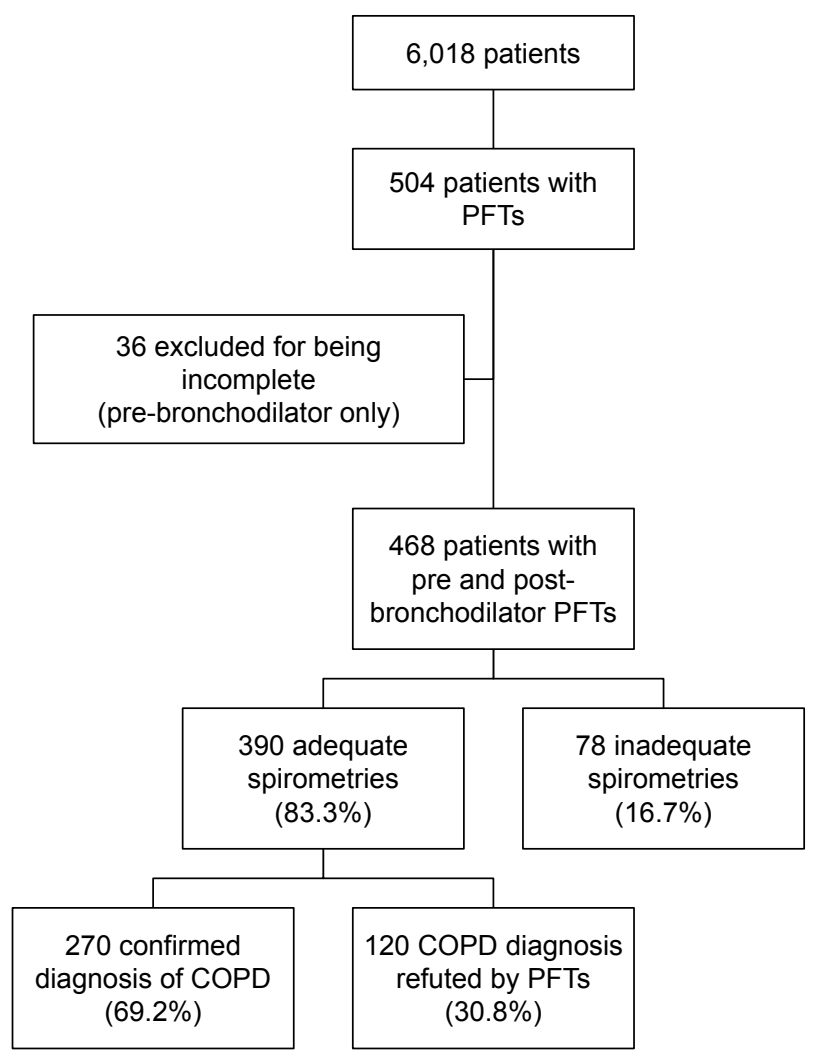

Figure I Flowchart for patients.

Abbreviations: COPD, chronic obstructive pulmonary disease; PFTs, pulmonary function tests.

Higher pack-year history of smoking (more than 30 years) was significantly more likely to be associated with COPD $(P=0.0003)$ (Table 1).

An underweight BMI was significantly different between patients with COPD and those without COPD. Those without COPD had a mean BMI of $35.55 \mathrm{~kg} / \mathrm{m}^{2}(\mathrm{SD}=12.10)$, while those with COPD had a mean BMI of $29.55 \mathrm{~kg} / \mathrm{m}^{2}$ $(\mathrm{SD}=9.87)$, which was a statistically significant difference $(P$-value $=0.0001)$.

Table I Characteristics of patients in study

\begin{tabular}{|c|c|c|c|}
\hline & COPD, $\mathbf{N}=\mathbf{2 7 0}$ & Not COPD, $\mathbf{N}=120$ & $P$-value \\
\hline Age, years (mean) & $70.08(\mathrm{SD}=12.29)$ & $68.31(\mathrm{SD}=\mid 3.99)$ & 0.21 \\
\hline Sex (males) & 113 (4I.9\%) & 45 (37.5\%) & 0.41 \\
\hline Race (Caucasian) & $253(93.7 \%)$ & $106(88.3 \%)$ & 0.07 \\
\hline BMI (mean) & $29.55(\mathrm{SD}=9.87)$ & $35.55(\mathrm{SD}=12.10)$ & 0.0001 \\
\hline Current smokers & 85 (3I.5\%) & $28(23.3 \%)$ & 0.10 \\
\hline Former smokers & I5I (55.9\%) & $54(45.0 \%)$ & 0.047 \\
\hline Never smokers & 30 (II.1\%) & $34(28.3 \%)$ & 0.0001 \\
\hline I-15 pack-years & $21(7.7 \%)$ & $13(10.9 \%)$ & 0.318 \\
\hline 16-30 pack-years & $54(20 \%)$ & $23(19.2 \%)$ & 0.873 \\
\hline $31+$ pack-years & 118 (43.7\%) & $29(29.2 \%)$ & 0.0003 \\
\hline
\end{tabular}

Abbreviations: BMI, body mass index; COPD, chronic obstructive pulmonary disease. 


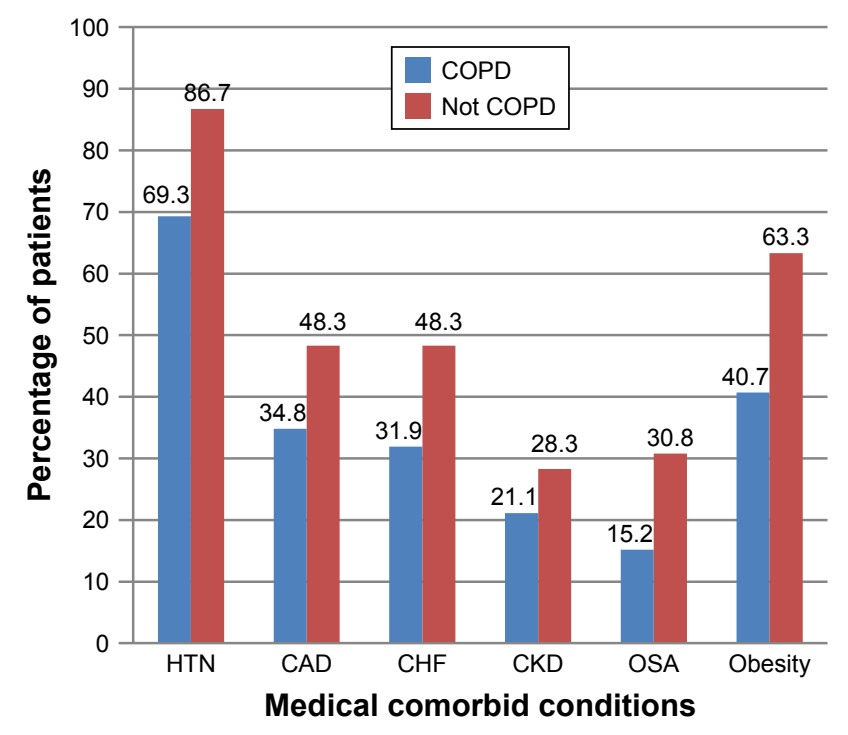

Figure 2 Proportion of patients with diagnosis based on medical comorbidities. Note: Obesity defined as body mass index $>30 \mathrm{~kg} / \mathrm{m}^{2}$.

Abbreviations: CAD, coronary artery disease; CHF, congestive heart failure; CKD, chronic kidney disease; COPD, chronic obstructive pulmonary disease; HTN, hypertension; OSA, obstructive sleep apnea.

Medical comorbidities were more commonly seen in patients without COPD compared to those with COPD by spirometry. Of the six medical comorbidities examined, more patients without COPD were found to have statistically significant higher rates of systemic hypertension, coronary artery disease, congestive heart failure, obstructive sleep apnea, and obesity (all $P$-values $<0.04$ ) (Figure 2).

These spirometry studies were also analyzed using the LLN definitions for COPD. ${ }^{19}$ Comparing patients with COPD by GOLD and by LLN revealed 29 patients (10.7\%) who were classified as having COPD by GOLD who were classified as normal by LLN. Characteristics of those that were not COPD by LLN showed a higher mean age of 75.83 $(\mathrm{SD}=12.57)$, compared to $70.08(\mathrm{SD}=12.29, P$-value $=0.008)$ (Table 2).
In the subset of 120 patients without COPD on spirometry, 53 patients (44\%) were sent home with the diagnosis of COPD on their discharge summary. Fewer but still significant numbers of patients were discharged with oral steroids (32 patients, $28.3 \%$ ) and maintenance inhalers commonly used to treat COPD (39 patients, 32.5\%).

\section{Discussion}

Despite studies confirming the validity of spirometry in hospitalized patients, it is not routinely utilized to confirm the diagnosis of COPD. ${ }^{29,30}$ In this retrospective study of 6,018 patients admitted with a principle diagnosis of COPD, the use of spirometry to confirm the diagnosis of COPD is very low at $8.4 \%(504 / 6,018)$. Other studies have documented the low use of spirometry in the outpatient and hospital setting. ${ }^{23-29}$ The history and physical examination are nonspecific and not sufficient to make a confident diagnosis of COPD. Spirometry is a simple, widely available, inexpensive, bedside, safe, and standardized test with international guidelines. In contrast to other common diagnoses like congestive heart failure, which must be verified with echocardiography, there are no quality control measures that enforce the documentation of COPD by using spirometry. ${ }^{30}$

The low use of spirometry to confirm the diagnosis may be attributed to many factors. There may be a lack of understanding of the definition of COPD that requires airflow obstruction, which is not completely reversible after bronchodilation. Many clinicians may have the impression that spirometry is difficult to perform in hospitalized patients or that they would want to defer the pulmonary function testing until after discharge. Although it is true that spirometry is an effort-dependent test, the majority of patients in this study were able to perform the test and produce acceptable results. The average age of patients in this study was 70 years. Patients were admitted with clinically decompensated

Table 2 Characteristics of patients with COPD by GOLD criteria compared to those with COPD by LLN

\begin{tabular}{llll}
\hline & $\begin{array}{l}\text { COPD by GOLD, } \\
\mathbf{N}=\mathbf{2 7 0}\end{array}$ & $\begin{array}{l}\text { COPD by LLN, } \\
\mathbf{N}=\mathbf{2 4} \text { I }\end{array}$ & $\begin{array}{l}\text { COPD by GOLD, but not } \\
\text { COPD by LLN, N=29 }\end{array}$ \\
\hline Age (mean) & $70.08(\mathrm{SD}=12.29)$ & $69.39(\mathrm{SD}=12.107)$ & $75.83(\mathrm{SD}=12.57)$ \\
Sex (males) & $113(41.9 \%)$ & $98(40.6 \%)$ & $15(51.7 \%)$ \\
Race (Caucasian) & $253(93.7 \%)$ & $226(93.7 \%)$ & $27(93.1 \%)$ \\
BMI (mean) & $29.55(\mathrm{SD}=9.87)$ & $29.05(\mathrm{SD}=9.83)$ & $33.77(\mathrm{SD}=9.32)$ \\
Current smokers & $85(31.5 \%)$ & $81(33.6 \%)$ & $5(17.2 \%)$ \\
Former smokers & $137(50.7 \%)$ & $135(56 \%)$ & $9(31 \%)$ \\
Never smokers & $44(16.3 \%)$ & $24(9.9 \%)$ & $13(44.8 \%)$ \\
I-I5 years pack-years & $21(7.7 \%)$ & $19(7.8 \%)$ & $2(6.8 \%)$ \\
I6-30 pack-years & $54(20 \%)$ & $47(19.5 \%)$ & $7(24 \%)$ \\
3 I+ pack-years & II8 (43.7\%) & $108(44.8 \%)$ & $11(37.9 \%)$
\end{tabular}

Abbreviations: BMI, body mass index; COPD, chronic obstructive pulmonary disease; GOLD, Global Initiative for Chronic Obstructive Lung Disease; LLN, lower limit of normal. 
respiratory status, yet $88.3 \%$ were able to perform the test well and meet the acceptability and reproducibility criteria of ATS-ERS.

There may also be a prevailing belief among clinicians that patients with the diagnosis of COPD have had prior spirometry confirming the diagnosis. However, a study found that most hospitalized patients admitted with COPD were never tested prior to admission. ${ }^{10}$ Stein et al showed that of all the patients admitted with COPD, only $20.8 \%$ had confirmatory spirometry in the prior 2 years. ${ }^{10}$ Another reason for not performing spirometry is that the physician may want to wait until the patient is clinically stable and no longer has an acute exacerbation. Rea et al demonstrated that spirometry performed in the hospital was useful to detect airflow obstruction. Moreover, spirometry done one month after discharge from the hospital did not result in a significant change in the overall diagnosis of these patients. ${ }^{11}$ Unfortunately, some patients may become lost to follow-up and will never have the appropriate testing to confirm the diagnosis.

The major finding in this study was that 30.8\% (120/390) of hospitalized patients had spirometry that was not consistent with the diagnosis of COPD by GOLD. In the outpatient primary care setting, Walters et al found that $31.8 \%$ of patients had spirometry that was not confirmatory of COPD. ${ }^{14}$ Of the 120 patients whose spirometry did not reveal airflow obstruction, 104 patients were diagnosed with restrictive lung disease and 16 had normal studies.

Of the 120 patients who had negative spirometry for COPD (misdiagnosed), $44 \%$ continued to carry the diagnosis upon discharge. Over $30 \%$ of these patients were sent home with medications to treat COPD such as steroids and bronchodilators. Although the number who had PFTs is a small sample of the total patients, extrapolation of this rate to the total 6,018 patients in this study translates into a potential number of 1,800 patients with a likelihood of being misdiagnosed, mistreated, and subjected to harmful medications with excessive cost. The Institute of Medicine has recently warned that there is a major issue of misdiagnosis and called for caution. They warned that there is a failure to establish an accurate and timely explanation of the patients' health problems, as well as a failure to communicate the explanation to the patient. ${ }^{31}$ In order to improve on the quality of care provided to COPD patients, an accurate diagnosis is essential. Furthermore, inaccurate diagnoses result in errors in coding, reimbursement, and quality improvement initiative monitoring.

As hospitalized patients get older, the overdiagnosis of COPD will likely worsen. This study revealed that $10.7 \%(29 / 270)$ of spirometry studies diagnosed as airflow obstruction by GOLD criteria would have been considered normal by LLN criteria. The average age of these 29 patients was 75 years compared to 70 years in the COPD by GOLD group. Nearly half of these patients were never smokers.

Comparing misdiagnosed patients to those with appropriate diagnosis of COPD, it was found that there was no difference with regard to age, race, or sex. The average age of patients in this study is 70 years, which is older than other studies. ${ }^{23-29}$ The majority were Caucasians with a male to female ratio of 2:3. Previous studies performed in the veteran hospitals were more heavily weighted toward male patients. According to Centers for Disease Control hospital discharge data, women have surpassed men in the number of COPD hospitalizations in the US since the mid 1990s. Worldwide, COPD affects men and women equally. ${ }^{3}$ Thus, this study reflects a true sample of the community.

Patients diagnosed with COPD were statistically more likely to be current or former smokers, with a pack-year history greater than 30 years. Misdiagnosis was more likely in patients with no smoking history. Consistent with the findings of others, misdiagnosed patients had a higher mean BMI. ${ }^{32-35}$ The mean BMI of the misdiagnosed patients in this study was $36.64 \mathrm{~kg} / \mathrm{m}^{2}$, while those with COPD had a mean BMI of $29.55 \mathrm{~kg} / \mathrm{m}^{2}$. The majority of patients in the cohort were overweight or obese and there were significant numbers of patients with COPD who were in these categories.

The literature does not focus on other comorbidities for misdiagnosis. ${ }^{36}$ In this study, there is a significant correlation between presence of hypertension, coronary artery disease, congestive heart failure, and obstructive sleep apnea and the misdiagnosis of COPD. Smoking is a common risk factor for both heart and lung diseases. Similar symptomatology of dyspnea, cough, wheezing, and hypoxemia can be seen in many diseases. This study revealed that the presence of these comorbid conditions should prompt the physician to evaluate for other causes of symptoms. Spirometry is a simple, bedside test that can be used to differentiate between the conditions.

The major limitation of this study was that the design was a retrospective, single-center study using ICD codes to identify patients. The reason why some patients had confirmatory testing while the majority did not have was unclear. The design of the study did not allow for searching for spirometry testing prior to or after hospitalization. Further studies need to address the reasons why spirometry is not used in hospitalized patients despite the evidence that it is an accurate test even in patients who are acutely ill.

The strength of this study was that it was conducted in a community teaching hospital and it reflects real-world 
practice of acutely ill patients admitted with decompensation of pulmonary status. The patient population was of diverse age range, but average age was more than that in previous studies. Women were appropriately represented. The study was performed after national and international guidelines requiring the use of spirometry for the proper diagnosis of COPD have been disseminated. Updates to the GOLD criteria have been published and continue to reaffirm the importance of spirometry for the verification of this common diagnosis.

\section{Conclusion}

One out of three patients admitted to the hospital with the diagnosis of COPD may be misdiagnosed and mistreated. Obesity, obstructive sleep apnea, hypertension, coronary artery disease, and congestive heart failure were strongly associated with comorbidity attributed to misdiagnosis. The suspicion for a proper diagnosis of COPD should be higher in current and former smokers, those with higher pack-year smoking history, and low BMI. However, regardless of suspicion, more patients should have confirmatory testing performed while in the hospital to avoid misdiagnosis.

\section{Acknowledgment}

The authors thank Christen Adams, MS, and Tara Knisely, $\mathrm{MPH}$, for their assistance in the data analysis.

\section{Author contributions}

KS had access to all the study data and takes full responsibility for the integrity of the data and the accuracy of the analysis. FK and KS contributed to the study design, data analysis, and manuscript writing. LB assisted in data gathering; FK and GB evaluated the spirometry studies. KRB contributed to data analysis and manuscript writing. All authors contributed toward data analysis, drafting and critically revising the paper, gave final approval of the version to be published, and agree to be accountable for all aspects of the work.

\section{Disclosure}

The authors report no conflicts of interest in this work.

\section{References}

1. Guarascio AJ, Ray SM, Finch CK, Self TH. The clinical and economic burden of chronic obstructive pulmonary disease in the USA. Clinicoecon Outcomes Res. 2013;5:235-245.

2. Mathers CD, Loncar D. Projections of global mortality and burden of disease from 2002 to 2030. PLoS Med. 2006;3(11):e442.

3. World Health Organization. Chronic obstructive pulmonary disease fact sheet, updated Nov 2016. Available from: http://www.who.int/ mediacentre/factsheets/fs315/en/. Accessed June 6, 2017.

4. Lopez AD, Shibuya K, Rao C, et al. Chronic obstructive pulmonary disease: current burden and future projections. Eur Respir J. 2006; 27(2):397-412.
5. Simon PM, Schwartzstein RM, Weiss JW, Fencl V, Teghtsoonian M, Weinberger SE. Distinguishable types of dyspnea in patients with shortness of breath. Am Rev Respir Dis. 1990;142(5):1009-1014.

6. Kessler R, Partridge MR, Miravitlles M, et al. Symptom variability in patients with severe COPD: a pan-European cross-sectional study. Eur Respir J. 2011;37(2):264-272.

7. Espinosa de los Monteros MJ, Peña C, Soto Hurtado EJ, Jareño J, Miravitlles M. Variability of respiratory symptoms in severe COPD. Arch Broncopneumol. 2012;48(1):3-7.

8. Mannino DM, Etzel RA, Flanders WD. Do the medical history and physical examination predict low lung function? Arch Intern Med. 1993; 153(16):1892-1897.

9. Holleman DR Jr, Simel DL. Does the clinical examination predict airflow limitation? JAMA. 1995;273(4):313-319.

10. Stein BD, Bautista A, Schumock GT, et al. The validity of International Classification of Diseases, Ninth Revision, Clinical Modification diagnosis codes for identifying patients hospitalized with COPD exacerbations. Chest. 2012;141(1):87-93.

11. Rea H, Kenealy T, Adair J, Robinson E, Sheridan N. Spirometry for patients in hospital and one month after admission with an acute exacerbation of COPD. Int J Chron Obstruct Pulmon Dis. 2011;6:527-532.

12. Global Initiative for Chronic Obstructive Lung Disease (GOLD). Global strategy for diagnosis, management, and prevention of COPD, updated 2017. Available from: http://goldcopd.org/gold-reports/. Accessed June 6, 2017.

13. Bernd L, Joan BS, Michael S, et al; BOLD Collaborative Research Group, the EPI-SCAN Team, the PLATINO Team, and the PREPOCOL Study Group. Determinants of underdiagnosis of COPD in national and international surveys. Chest. 2015;148(4):971-985.

14. Walters JA, Walters EH, Nelson M, et al. Factors associated with misdiagnosis of COPD in primary care. Prim Care Respir J. 2011;20(4): 396-402.

15. Arne M, Lisspers K, Ställberg B, et al. How often is diagnosis of COPD confirmed with spirometry? Respir Med. 2010;104(4):550-556.

16. Hardie JA, Buist AS, Vollmer WM, Ellingsen I, Bakke PS, Mørkve O. Risk of over-diagnosis of COPD in asymptomatic elderly never-smokers. Eur Respir J. 2002;20(5):1117-1122.

17. Janssens JP, Pache JC, Nicod LP. Physiological changes in respiratory function associated with ageing. Eur Respir J. 1999;13(1):197-205.

18. Prieto-Centurion V, Rolle AJ, Au DH, et al; CONCERT Consortium. Multicenter study comparing case definitions used to identify patients with chronic obstructive pulmonary disease. Am J Respir Crit Care Med. 2014;190(9):989-995.

19. Ghattas C, Dai A, Gemmel DJ, Awad MH. Over diagnosis of chronic obstructive pulmonary disease in an underserved patient population. Int J Chron Obstruct Pulmon Dis. 2013;8:545-549.

20. Collins BF, Feemster LC, Rinne ST, Au DH. Factors predictive of airflow obstruction among veterans with presumed empirical diagnosis and treatment of COPD. Chest. 2015;147(2):369-376.

21. Güder G, Brenner S, Angermann CE, et al. "GOLD or lower limit of normal definition? A comparison with expert-based diagnosis of chronic obstructive pulmonary disease in a prospective cohort-study". Respir Res. 2012;13(1):13.

22. Miller MR, Harkinson J, Brusasco V, et al; ATS/ERS Task Force. Standardisation of spirometry. Eur Respir J. 2005;26(2):319-338.

23. Bolton CE, Ionescu AA, Edwards PH, Faulkner TA, Edwards SM, Shale DJ. Attaining a correct diagnosis of COPD in general practice. Respir Med. 2005;99(4):493-500.

24. Tinkelman DG, Price DB, Nordyke RJ, Halbert RJ. Misdiagnosis of COPD and asthma in primary care patients 40 years of age and over. J Asthma. 2006;43(1):75-80.

25. Han MK, Kim MG, Mardon R, et al. Spirometry utilization for COPD: how do we measure up? Chest. 2007;132(2):403-409.

26. Lee TA, Bartle B, Weiss KB. Spirometry use in clinical practice following diagnosis of COPD. Chest. 2006;129(6):1509-1515.

27. Joo MJ, Sharp LK, Au DH, Lee TA, Fitzgibbon ML. Use of spirometry in the diagnosis of COPD: a qualitative study in primary care. COPD. 2013;10(4):444-449. 
28. Gershon AS, Hwee J, Croxford R, Aaron SD, To T. Patient and physician factors associated with pulmonary function testing for COPD: a population study. Chest. 2014;145(2):272-281.

29. Prieto Centurion V, Huang F, Naureckas ET, et al. Confirmatory spirometry for adults hospitalized with a diagnosis of asthma or chronic obstructive pulmonary disease exacerbation. BMC Pulm Med. 2012;12:73.

30. Damarla M, Celli BR, Mullerova HX, Pinto-Plata VM. Discrepancy in the use of confirmatory tests in patients hospitalized with the diagnosis of chronic obstructive pulmonary disease or congestive heart failure. Respir Care. 2006;51(10):1120-1124.

31. McGlynn EA, McDonald KM, Cassel CK. Measurement is essential for improving diagnosis and reducing diagnostic error: a report from the Institute of Medicine. JAMA. 2015;314(23):2501-2502.

32. Sin DD, Jones RL, Man SF. Obesity is a risk factor for dyspnea but not for airflow obstruction. Arch Intern Med. 2002;162(13):1477-1481.
33. Collins BF, Ramenofsky D, Au DH, Ma J, Uman JE, Feemster LC. The association of weight with the detection of airflow obstruction and inhaled treatment among patients with a clinical diagnosis of COPD. Chest. 2014;146(6):1513-1520.

34. Salome CM, King GG, Berend N. Physiology of obesity and effects on lung function. J Appl Physiol (1985). 2010;108(1):206-211.

35. O'Donnell DE, Deesomchok A, Lam YM, et al. Effects of BMI on static lung volumes in patients with airway obstruction. Chest. 2011; 140(2):461-468.

36. Schnell K, Weiss CO, Lee T, et al. The prevalence of clinically-relevant comorbid conditions in patients with physician-diagnosed COPD: a cross-sectional study using data from NHANES 1999-2008. BMC Pulm Med. 2012;12:26.
International Journal of COPD

\section{Publish your work in this journal}

The International Journal of COPD is an international, peer-reviewed journal of therapeutics and pharmacology focusing on concise rapid reporting of clinical studies and reviews in COPD. Special focus is given to the pathophysiological processes underlying the disease, intervention programs, patient focused education, and self management protocols.

\section{Dovepress}

This journal is indexed on PubMed Central, MedLine and CAS. The manuscript management system is completely online and includes a very quick and fair peer-review system, which is all easy to use. Visit http://www.dovepress.com/testimonials.php to read real quotes from published authors.

Submit your manuscript here: http://www.dovepress.com/international-journal-of-chronic-obstructive-pulmonary-disease-journal 